\title{
Tecnologia assistiva para crianças cegas: produtos de apoio para a mobilidade pessoal
}

\author{
Lana Tuan Borges de Jesus* \\ Alexandra da Silva Santos Sampaio** \\ Maria Helena Silveira Bonilla***
}

\section{Resumo}

O objetivo deste artigo consiste em identificar, catalogar e descrever a funcionalidade dos recursos de tecnologia assistiva, em especial os produtos de apoio para orientação e mobilidade da criança cega na faixa etária de 0 a 5 anos, utilizados para potencializar o seu desenvolvimento sensório-motor, reduzir ou eliminar as possíveis limitações causadas pela deficiência. A revisão bibliográfica prévia demonstrou que são escassos os estudos e trabalhos científicos sobre Tecnologia Assistiva específica para este público, na faixa etária estudada, o que torna este artigo de singular relevância tanto para a área quanto socialmente. Os resultados iniciais indicaram que há falta de correlação entre os produtos disponíveis como sendo Tecnologia Assistiva, além de revelar que os produtos de apoio devem seguir preceitos e critérios individualizados, considerando as necessidades específicas e individuais, o contexto que a criança cega está inserida e as barreiras que impedem ou dificultam a execução da tarefa pelo indivíduo, destacamos que todos os produtos identificados são físicos, analógicos, podendo ser confeccionados de modo artesanal, com custos mínimos e alta funcionalidade, entretanto, a falta de produtos digitais específicos para as crianças cegas, na faixa etária estudada, evidencia o estágio em que se encontra o desenvolvimento tecnológico nessa área e/ou o pouco investimento feito para o atendimento desses sujeitos.

Palavras-chave: Tecnologia Assistiva; Orientação e Mobilidade; Criança cega.

\footnotetext{
* Mestranda em Educação pela Universidade Federal da Bahia. Salvador, Bahia, Brasil.

** Mestranda em Educação pela Universidade Federal da Bahia. Salvador, Bahia, Brasil.

*** Professora doutora da Universidade Federal da Bahia. Salvador, Bahia, Brasil.
} 


\section{Assistive technology for blind children: product support for personal mobility}

\section{Abstract}

The purpose of this article is to identify, catalog and describe the functionality of assistive technology resources, especially in products to support orientation and mobility of blind children aged 0-5 years, used to increase their sensor and motor development and to reduce or eliminate the possible limitations caused by the disability. The previous literature review has shown that there are few scientific studies and papers on assistive technology specific to this audience, at the studied age group, which makes this a study of unique relevance to both the field, and society. Initial results indicated that the products available as Assistive Technology should follow instructions and individualized criteria, considering the specific and individual needs, the context the blind child is inserted and the barriers that make harder to execute tasks. We emphasize that all products identified are physical, analogic, and can be handcrafted with minimum cost and high functionality, and that there is a lack of digital products specifically made for blind children in the studied age group, which shows the development stage of technology in this area and/or the little investment made to treat these subjects.

Keywords: Assistive Technology; Orientation and Mobility; Blind Child.

\section{Introdução}

De maneira geral, podemos dizer que o desenvolvimento da criança, após o nascimento, engloba três etapas principais: neurológica, psicológica e motora. Nesse processo, com o passar do tempo, vão ocorrendo modificaçóes em todo o organismo, e, para que seja alcançado o pleno desenvolvimento, é necessária toda uma ação conjunta entre os sistemas que formam o corpo humano, devendo estes funcionarem o mais harmoniosamente possível.

Diem (1980) enfatizou que a aquisição das funçóes motoras ocorre através de um aprendizado, tanto por conta dos próprios movimentos como também através da imitação dos gestos de adultos e outras crianças que os rodeiam. Portanto, para o autor, a visão tem papel fundamental no desenvolvimento do sujeito, tanto por ser através dela que este pode ter acesso às informaçôes e experiências necessárias para seu aprendizado quanto pela íntima relação da visão com o cérebro.

O desenvolvimento do sistema vestibular começa nas semanas iniciais da gestação e tem um papel relevante no desenvolvimento inicial da criança, uma vez que é ele quem permite a percepção do movimento, o grau de equilíbrio do corpo, a manutenção da postura corporal e da cabeça e, ainda, a movimentação corporal e dos olhos. Influencia, também, o desenvolvimento e manutenção do tônus muscular, que é fundamental para a realização do movimento. 
No entanto, Ochaita e Espinosa (2004) destacam que a cultura ocidental atribui papel preponderante à visão, desconsiderando, muitas vezes, as qualidades das interaçôes sociais como fator crucial no processo de desenvolvimento. Ao considerar a criança com perda visual severa, Bruno (1993, p. 11) afirma que "a ação do sujeito portador de deficiência visual e sua capacidade de construir conhecimento ficam muitas vezes prejudicadas, não pela limitação do déficit visual em si, mas, principalmente, pela qualidade de troca com o meio". Portanto, não cabe pensar o desenvolvimento meramente pela dimensáo biofisiológica, mas como aponta os estudos de Vygotski (1984), é a interação significativa entre os sujeitos e as intervençôes do meio externo que criam possibilidades para o avanço cognitivo, afinal, o sujeito se constrói no social, histórica e culturalmente.

As questôes biológicas, sociais, culturais e históricas se relacionam entre si e terâo influência no desenvolvimento do sujeito, inclusive na criança com deficiência. Para Vygotski (1997), existe a deficiência primária, relacionada aos problemas de ordem orgânica/ biológica e a deficiência secundária, que engloba as consequências psicossociais da deficiência. Segundo o autor, na maioria das vezes "Las consecuencias sociales del defecto acentúan, alimentan y consolidan el propio defecto. En este problema no existe aspecto alguno donde lo biológico pueda ser separado de lo social" (p. 93). Sendo assim, o social engloba desde as relaçôes interpessoais até os produtos, recursos, metodologias, estratégias, práticas, serviços e outros. Portanto, os recursos de apoio, como as tecnologias assistivas, devem basear-se numa abordagem "biopsicossocial", que concebe o sujeito em suas múltiplas dimensôes.

Então, a Tecnologia Assistiva (TA) surge, para a criança cega, como uma intervençáo externa que visa minimizar os efeitos da deficiência e possibilitar sua plena autonomia. De acordo com Sartoretto e Bersch (2013), a TA é um termo ainda novo, utilizado para identificar todo o arsenal de Recursos e Serviços que contribuem para proporcionar ou ampliar habilidades funcionais de pessoas com deficiência e, consequentemente, promover vida independente e inclusão.

Para Bruno (1993, p.18), devido a pouca movimentação espontânea integrada e do giro cefálico pobre, a criança com perda visual "apresenta baixa reação vestibular e por isso rejeita terminantemente a movimentaçáo e mudança postural, mostrandose tensa e insegura aos movimentos do corpo. Isso prejudica a formaçáo de equilíbrio e os primeiros deslocamentos no espaço". Sendo assim, a tecnologia assistiva pode atuar estas limitaçóes de modo a estimular a ampliação das habilidades motoras deste indivíduo, pois, como afirma Radabaugh (1993, p. 1), "Para as pessoas sem deficiência, a tecnologia torna as coisas mais fáceis. Para as pessoas com deficiência, a tecnologia torna as coisas possíveis".

Partindo da afirmativa acima, surge o seguinte questionamento: como a Tecnologia Assistiva pode favorecer a autonomia e independência da criança cega, no que tange ao seu desenvolvimento sensório-motor, na tentativa de minimizar os efeitos da deficiência e potencializar o desenvolvimento da marcha, favorecendo a mobilidade? 
Tendo em vista a complexidade do desenvolvimento humano e a multiplicidade de alterações que ocorrem, especialmente nos primeiros anos de vida, esse trabalho fará, inicialmente, um estudo sobre o desenvolvimento motor e aquisição da marcha da criança cega, na faixa etária de 0 a 5 anos, com ênfase na importância do sistema vestibular e nas possíveis implicaçóes da deficiência nestes. Somente com base nessa compreensão, as contribuições da Tecnologia Assistiva poderão se tornar evidentes, uma vez que produtos assistivos, simples e/ou confeccionados artesanalmente, são extremamente funcionais e podem constituir-se em intervençóes potencializadoras do desenvolvimento sensório-motor destes sujeitos.

Logo, o objetivo geral deste estudo consiste em identificar, catalogar e descrever a funcionalidade dos produtos de Tecnologia Assistiva, direcionados ao apoio para a mobilidade pessoal que favoreçam a orientação, aquisição da marcha e melhora da mobilidade de crianças cegas na faixa etária de 0 a 5 anos. Esperamos, com a elaboraçáo deste estudo, ampliar as produçóes acadêmicas sobre produtos de apoio utilizados no processo de aprendizagem da Orientação e Mobilidade (OM) das crianças cegas, conforme garantido na Política Nacional de Educação Especial (BRASIL, 2008) e outros documentos legais. ${ }^{2}$

\section{Desenvolvimento sensório - motor da criança cega na faixa etária de 0 a 5 anos}

De acordo com Shumway-Cook e Woollacott (2003), o movimento constitui-se aspecto imprescindível da vida, sendo fundamental para o desenvolvimento de capacidades como comer, brincar, caminhar, se comunicar, etc. A capacidade de regular ou orientar os mecanismos essenciais para o movimento é chamado de controle motor, o qual, por sua vez, refere-se "ao controle dos músculos e ao movimento resultante dos membros e do tronco: é o mesmo que controle do movimento" (LOPES, 2008, p. 54).

A gênese do movimento se dá pela interação entre o indivíduo, a tarefa e o ambiente, emergindo através da cooperação entre diversas e distintas estruturas e processos, incluindo o neurológico, ou seja, ele surge da relaçáo entre processos complexos, abrangendo a percepção, a cogniçẫo e a ação propriamente dita. Por conta disso, é importante destacar que "a pesquisa do controle motor que se concentra apenas nos processos que ocorrem dentro do indivíduo, sem levar em consideração o ambiente no qual ele se move ou a tarefa que está sendo executada, produzirá um quadro incompleto" (SHUMWAY-COOK e WOOLLACOTT, 2003, p. 2).

Segundo Bruno (1993, p.14), o desenvolvimento perceptivo da criança em geral e, especialmente, da criança com perda visual severa, depende de experiências sensório-motoras integradas, pois estas vivências possibilitarão melhor organização, planejamento das açôes motoras, percepção espacial, entre outros. Em decorrência da baixa atividade motora, proprioceptiva e vestibular, a criança cega "tem pouca oportunidade de prolongar as experiências táteis-cinestésicas: de flexão do corpo, da sucção dos dedos e roçar do rosto, que vivenciaram no útero materno", açóes que são de extrema importância para a exploração tátil, conhecimento corporal e do meio. 
O sistema vestibular ${ }^{3}$ que se desenvolve nas primeiras semanas gestacional desempenha importante papel no desenvolvimento inicial da criança, pois fornece informaçôes sensoriais aferentes ${ }^{4}$ sobre os movimentos oculares e as posiçôes cefálicas em referência a gravidade, permitindo, assim, a percepção do movimento ocular e corporal, e do grau de equilíbrio cefálico e corporal, além de influenciar o desenvolvimento e manutenção do tônus muscular ${ }^{5}$. Conforme Shumway-Cook e Woollacott (2003), todas estas informaçôes são usadas para estabilização do olhar, da postura e do equilíbrio.

Dessa forma, é relevante sua contribuição para a sensação de forma consciente e da orientaçấo espacial, sendo que os distúrbios funcionais do sistema vestibular podem provocar desde desestabilização do olhar, até comprometimentos da postura e do equilíbrio. Isso ganha relevância especial em se tratando de crianças, uma vez que essa disfunção pode ter impacto direto no desenvolvimento destas.

Em virtude de toda a complexidade do desenvolvimento motor, da percepção, e da realização do movimento em si, e considerando as características específicas da criança cega, é fundamental o entendimento acerca dos processos de aprendizagem motora, dos seus mecanismos principais e, principalmente, dos meios de facilitação possíveis que favoreçam a realização da atividade motora neste público, além de potencializar a plasticidade neural. ${ }^{6}$

Para Ochaíta e Espinosa (2004), é no período de 5 a 6 meses que os bebês, além do interesse pelas pessoas próximas, também começam a nutrir atenção pelos objetos em sua volta. Bruno (1993) acrescenta que, nesta fase, a criança cega executa pouco exercício de rotaçáo cefálica a partir da busca auditiva, pois, inicialmente, o processo de busca da fonte sonora tem relaçáo direta com a busca visual.

Então, se as crianças com perda visual severa não forem estimuladas "tendem a permanecer por mais tempo em assimetria, com cabeça lateralizada, braços abertos e elevados, com mãos cerradas" (BRUNO, 1993, p.15). Nesta fase, o bebê cego, por ter pouca movimentação espontânea integrada e giro cefálico pobre, precisa ser auxiliado a mudar de posição (barriga para cima, para o lado, para baixo), pois desta maneira “[...] quando estiver com aproximadamente 8 meses ele ficará de barriga para baixo para que exercite ficar na posição de gatinho e posteriormente, engatinhar [...]” (TEIXEIRA et al, 2010, p. 5). Ao vivenciar a posição de bruços, a criança, aos poucos, vai adquirindo força muscular nos braços, usando as mãos com maior intensidade, além de possibilitar o seu deslocamento no espaço.

No que se refere à mobilidade do sujeito com perda visual severa, Galvão (2005, p.32) destaca que "a limitação quanto à mobilidade dificulta a construção da noçáo de espaço e o domínio do ambiente que a cerca, podendo levar a criança a atitudes de isolamento e auto-estimulaçáo, com conseqüentes comportamentos esteriotipados e maneirismos". O primeiro contato no meio familiar é imprescindível neste processo, pois os pais devem antecipar os acontecimentos (pistas auditivas) para que a criança comece a se organizar motoramente e, assim, adquira confiança na marcha. 
De acordo com Bruno (1993, p. 17), o "nó górdio do desenvolvimento destas crianças" está na impossibilidade de ver o objeto e com isso não antecipa a conduta de preensão. A autora defende que "na ausência da visão, a coordenação desses esquemas se fará pela integração dos esquemas táteis-cinestésicos-auditivos através das condutas de sucção e preensão" como meio de compensação.

Estas crianças necessitam de apoio e orientação nesse processo de descoberta do ambiente a sua volta. Apesar da ausência da visão "[...] muitas crianças com deficiência visual têm plena condição motora para marcha, porém não se deslocam por insegurança e medo de se moverem sem orientação e controle do ambiente, por isso adquirem a marcha por volta de um ano e meio ou mais [...]". (BRUNO, 1993, p. 19). Portanto, é a partir da organização das experiências sensório-motoras integradas, mediante a coordenação dos esquemas (audição-tátil-cinestésico-preensão), que este sujeito poderá ter um bom desenvolvimento global e, consequentemente, vivenciar situaçóes que lhe permitam explorar o mundo pelas vias perceptivas remanescentes, visando à autonomia.

De acordo com a Teoria Ecológica de Karl Newell (Shumway-Cook e Woollacott, 2003, apud Newell, 1991), a aprendizagem motora seria um "processo que aumenta a coordenação entre a percepção e a ação, de maneira consistente com as restriçôes da tarefa e do ambiente". Dessa forma, a Orientação e Mobilidade (OM) possibilitarão à criança cega ter locomoção independente em diversos ambientes e será uma prática ampliada com o passar dos anos e da maturidade, proporcionando confiança, auto-estima e melhor qualidade de vida, tendo na Tecnologia Assistiva uma importante aliada para seu pleno desenvolvimento.

\section{Tecnologia assistiva: contribuições aos programas de orientação e mobilidade}

De acordo com o Comitê de Ajudas Técnicas - CAT, da Secretaria dos Direitos Humanos da Presidência da República (SDH/PR), desde 2007, a Tecnologia Assistiva é definida como:

Área do conhecimento, de característica interdisciplinar, que engloba produtos, recursos, metodologias, estratégias, práticas e serviços que objetivam promover a funcionalidade, relacionada à atividade e participação de pessoas com deficiência, incapacidades ou mobilidade reduzida, visando sua autonomia, independência, qualidade de vida e inclusão social. (CAT, 2007).

Como uma das possibilidades de Recursos ${ }^{7}$ de tecnologia assistiva, encontram-se os produtos de apoio que, conforme consta na Norma Internacional ISO 9999:2007, são classificados em 11 classes diferentes, conforme podemos observar no (QUADRO 1) abaixo: 
Quadro 1- Produtos Assistivos

\begin{tabular}{|l|l|}
\hline Classe 03 & Produto de apoio para tratamento clínico individual \\
\hline Classe 05 & Produtos de apoio para treino de competências \\
\hline Classe 06 & Órteses e próteses \\
\hline Classe 09 & Produtos de apoio para cuidados pessoais e proteção \\
\hline Classe 12 & Produtos de apoio para a mobilidade pessoal \\
\hline Classe 15 & Produtos de apoio para atividades domésticas \\
\hline Classe 18 & Mobiliário e adaptaçóes para habitação e outros edifícios \\
\hline Classe 22 & Produtos de apoio para a comunicação e informação \\
\hline Classe 24 & Produtos de apoio para manuseamento de objetos de dispositivos \\
\hline Classe 27 & Produtos de apoio para melhoria do ambiente, máquinas e ferramentas \\
\hline
\end{tabular}

Fonte: Norma Internacional ISO $9999: 2007$

Para Effgen (2007, p. 383), a Tecnologia Assistiva se refere a "grande variedade de equipamentos e serviços utilizados para aumentar a capacidade, a participação em atividades, e eliminar limitaçóes funcionais que surjam como resultado de comprometimentos". Dessa forma, pode-se perceber que a TA configura-se como uma grande aliada no processo de desenvolvimento global da criança cega, destacando a sua importância na aquisição de habilidades para orientação, mobilidade e marcha deste público.

Segundo Farrel (2008, p.32), "a orientação e a mobilidade são duas capacidades associadas ao movimento e ao deslocamento independentes. A orientação envolve ter consciência do espaço e de onde estamos dentro dele (Onde eu estou? Aonde eu quero ir? Como faço para chegar lá?)", já a mobilidade é "a capacidade de se movimentar com segurança”. De acordo com Shumway-Cook e Woollacott (2003, p. 289), quando falamos de mobilidade, no sentido de locomoçáo, é imprescindível considerarmos três características principais, que são: a progressão, a estabilidade e a adaptação. ${ }^{8}$ São estas características que possibilitam a realização de um movimento adequado.

Conforme Garcia (2003, p.68), o desenvolvimento da Orientação e Mobilidade do sujeito com perda visual severa, como qualquer outro indivíduo, ocorre desde o nascimento, todavia, as crianças com deficiência visual necessitarão de um serviço de apoio especializado que ofereça um programa específico de estímulo a atividades motoras e de orientaçáo e mobilidade. Sabendo que este estudo compreende a faixa etária de 0 a 5, anos é imprescindível a atuação de uma equipe multidisciplinar, como ocorre em Programas de Intervenção Precoce, ${ }^{9}$ e o uso da TA a fim de favorecer o desenvolvimento global deste indivíduo.

Portanto, a utilização da TA no atendimento e estimulação precoce da criança cega possibilita aumentar, melhorar ou manter as capacidades funcionais do sujeito, favorece a execução da atividade, ${ }^{10}$ proporciona maior participaçáo, ${ }^{11}$ além de redu- 
zir ou eliminar as possíveis limitaçóes e as restriçóes ${ }^{12}$ provocadas pela deficiência, tendo como resultado uma melhor qualidade de vida destas crianças.

Dutra (2003, p.5, apud Goldman, 1969, p. 82) destaca ser de suma importância os programas de Orientação e Mobilidade e a utilização dos meios adequados, como as TA, pois estas favorecem a estimulaçáo tátil (produtos de apoio que exploram a diversidade de texturas, alto relevo, etc.), auditivos (produtos de apoio com efeitos sonoros, uso de guizos), educaçáo postural (produtos que auxiliam no controle do tronco) e outros que contribuem no processo da aquisição e desenvolvimento da orientação, mobilidade e marcha da criança cega. O autor ainda destaca que a ausência deste programa pode refletir negativamente no desenvolvimento motor destas crianças.

[...] uma grande maioria de crianças cegas nunca serão capazes de se locomoverem com independência, isto porque não receberam nenhum tipo de instrução de orientação e mobilidade ou (...) receberam de maneira insuficiente (...) Orientação e Mobilidade são necessidades primordiais e não devem ser ignoradas. (...) Ao tomar consciência da necessidade de desenvolver tais programas é que começaremos a ver que a maioria das crianças cegas se tornaram adultos capazes, independentes e livres. (DUTRA, 2003, p.5, apud GOLGMAN, 1969, p. 82).

É relevante que todos os profissionais que desenvolvem atividades com crianças com deficiências visuais dominem certos conhecimentos acerca da OM, inclusive os profissionais de educação especial, que, em conformidade com o texto do Comitê de Competência do Departamento de Educação dos Estados Unidos, "necessitam conhecer as habilidades básicas de mobilidade; os conceitos e as técnicas que antecedem a aprendizagem do uso da bengala-longa" (GARCIA, 2003, p.69). Estas técnicas (Técnica do Guia Vidente, Técnicas De Auto-Ajuda, Técnica de Proteçáo Superior, Técnica de Proteçâo Inferior e outras) são consideradas como Tecnologia Assistiva, assim como os produtos de apoio, que devem ser utilizados o mais precocemente possível, a fim de favorecer o domínio dos conceitos e a estimulação dos sentidos remanescentes, favorecendo, desta forma, o movimento, a orientação e a mobilidade pessoal.

Assim como os profissionais, a criança com deficiência visual também precisa que os conceitos básicos relacionados à Orientação e Mobilidade (OM) sejam bem estruturados, para que o seu aprendizado seja significativo e lhe proporcione uma movimentação com segurança, eficiência e o mais naturalmente possível. De acordo com Masi (2003, p.38), alguns desses conceitos, que são fundamentais, se referem ao conhecimento corporal, devendo ser enfatizados aspectos referentes ao esquema, conceito e imagem corporal, planos e partes do corpo, lateralidade e direcionalidade. A autora destaca que tais conceitos devem "ser enriquecidos com outros da mesma importância, como: posição e relação com o espaço, forma, medidas e açóes, ambiente, topografia, textura e temperatura”. 
Segundo Lora (2003, p. 58), além de compreender os conceitos acima apresentados, a criança com perda visual severa precisa que suas outras vias de percepção do mundo também sejam estimuladas. A audição ${ }^{13}$ o tato ${ }^{14}$ e o olfato ${ }^{15}$ serão fundamentais no aprendizado da Orientação e Mobilidade.

Nesse contexto, torna-se necessária a identificação de quais produtos assistivos serão mais relevantes e possíveis de serem utilizados por crianças cegas, na faixa etária de 0 a 5 anos, de modo a potencializar a aquisiçáo e desenvolvimento de suas habilidades motoras. Conforme apresentamos anteriormente, existem 11 diferentes classificaçóes para os produtos de TA (ISO 9999:2007), porém, neste estudo, pretendemos identificar, catalogar e descrever a funcionalidade apenas dos produtos de apoio situados na classe 12, que são aqueles específicos para apoio à mobilidade pessoal.

\section{A criança cega e os produtos de apoio para a mobilidade pessoal}

Antes da exposição dos dados sobre produtos de apoio que auxiliam na orientação e mobilidade pessoal de crianças cegas, precisamos compreender que a cegueira, conforme Martín (2010, p.43), é uma deficiência sensorial que se caracteriza "pela ausência total de visão ou a simples percepção de luz", logo, os produtos assistivos que apresentaremos a seguir (QUADRO 2) irão estimular os sentidos remanescentes para possibilitar o desenvolvimento global deste sujeito, em especial no que tange aos aspectos sensório-motores.

Quadro 2 - Produtos de apoio para orientaçấo e mobilidade da criança cega

\begin{tabular}{|c|}
\hline PRODUTOS DE APOIO PARA A MOBILIDADE PESSOAL \\
\hline Brinquedos Sonoros \\
\hline $\begin{array}{l}\text { Bola de Guizo, Chocalhos e outros brinquedos sonoros contribuem para que o bebê cego } \\
\text { possa "levantar e movimentar a cabeça, fortalecendo os músculos do pescoço e peito". } \\
\text { (SIAULYS, 2005, p. 17) }\end{array}$ \\
\hline Pulseirinha com guizos/ Guizo pé-mão \\
\hline $\begin{array}{l}\text { A pulseirinha com guizos e guizo pé-mão, de acordo com Siaulys (2005, p. 20), ajuda "o } \\
\text { bebê a pôr o dedo do pé na boca. Essa açấo, realizada naturalmente por todos os bebês } \\
\text { que enxergam, favorece a construçáo da imagem corporal e é importante para estimular o } \\
\text { movimento dos braços, pernas e corpo". }\end{array}$ \\
\hline Rodão \\
\hline $\begin{array}{l}\text { Rodão é uma câmara-de-ar cheia revestida com tecido. Quando a criança fica dentro do } \\
\text { rodáo com os braços livres pode mover-se com segurança e explorar os objetos. Isto ajuda } \\
\text { a fortalecer os músculos do pescoço e peito e desenvolver o controle cefálico (SIAULYS } \\
2005 \text {, p. 56) }\end{array}$ \\
\hline
\end{tabular}


Continuação quadro 2

\section{Calça da vovó ou Calça sensorial}

Produto de apoio importante para organizaçáo motora, tornando-se um elemento facilitador de mudanças posturais da criança cega. Segundo Bruno (1993, p.92), com a calça os bebês cegos vão se sentir confortáveis na posição de bruços e "para sentar ela facilita o controle do tronco, o equilíbrio, a rotação de cabeça, liberando as mãos para brincar". A autora ainda destaca que a calça deve ser recheada "com panos velhos como toalha, roupa de lâ, (nas pernas) lençóis, que a deixem pesada, mas bem flexível para os ajustes posturais", ressaltando que a parte da barriga deve ser mais leve, pois serve como travesseiro.

\section{Rolinho}

De acordo com Siaulys (2005, p. 42), o rolinho ajuda "o bebê a apoiar as mãos no chão, erguer-se, balançar-se e deslocar-se para a frente, deslizando sobre o rolo; isso vai ajudar a desenvolver o engatinhar".

\section{Quartito}

De acordo com Bruno (1993, p.94), o quartito foi projetado originalmente por Lilli Nielsen, uma dinamarquesa que trabalha com crianças cegas. Este produto de apoio tem como finalidade fazer com que a criança cega explore os objetos usando as mãos, pés, e todo o corpo, "desenvolvendo a percepção tátil, a imagem corporal e a construção da noção de espaço". No quartito os objetos com diversos sons, texturas e tamanhos são dependurados para que a criança exercite a preensão, além disso, "brincar sentada no quartito ajuda a manter a cabeça mais elevada".

\section{Varal Multissensorial}

Segundo Bruno (1993, p.95), o varal com objetos multissensoriais estimula todos os sentidos remanescentes da criança cega e "também favorece o exercício dos esquemas motores, podendo a criança aprender a brincar em diferentes posiçóes: decúbito lateral ${ }^{16}$, ventral ${ }^{17}$, sentada e em pé"

\section{Pré-bengala}

Algumas possibilidades de pré-bengala para crianças cegas são: Patinho ou carrinhos de madeira, Carrinho de boneca, bambolê ou brinquedos de rodinha e haste para empurrar (BRUNO, 1993 e SIAULYS, 2005). É importante destacarmos que colocar um peso no carrinho de boneca é suficiente para a criança não virar enquanto o empurra; ou o bambolê quando é transformado na forma de raquete, ou ao usar guizos no carrinho de madeira para que a criança tenha uma pista sonora. Todas estas intervençôes auxiliam no processo de orientação, marcha e mobilidade deste sujeito, portanto estes simples brinquedos, após sofrer estas alteraçôes, tornam-se produtos de tecnologia assistiva.

\section{Bengala Infantil}

Bengala dobrável, medindo $80 \mathrm{~cm}$, dotada de ponteira com rolamento. Segundo Siaulys (2005, p. 101), a bengala infantil proporciona maior liberdade do movimento e deslocamento no espaço com segurança, além disso, "vai aumentar a autonomia e a autoconfiança da criança e, quanto mais cedo ela se familiarizar com este importante instrumento de independência, mais vai conhecer o ambiente e melhor será o seu processo de desenvolvimento". 
Continuação quadro 2

\section{Corrimáo e Caminhos sensoriais}

Segundo Bruno (1993, p.116), "o corrimão, caminhos sensoriais de texturas diferentes associados a estímulos auditivos, colocados ao longo da parede ou no solo, motivam a criança a engatinhar e andar". Estas alteraçóes no ambiente contribuem no processo de desenvolvimento da "intencionalidade, a sequência de açóes e adquirir noção de rastreamento táo necessária à orientação e mobilidade”.

Fonte: Elaboraçáo e sistematização das autoras

É importante destacarmos que todos estes produtos são físicos, analógicos, e que podem ser confeccionados artesanalmente, com baixo custo e extremamente funcionais, possibilitando à criança cega, desde o nascimento, ser estimulada a orientar-se e mover-se com segurança. Contemporaneamente, para além dos produtos analógicos, com o desenvolvimento vertiginoso da tecnologia, os recursos digitais vêm assumindo cada vez mais relevância. Galvão Filho (2012) destaca que os recursos de TA relacionados a esta área apresentam acelerados avanços "abrindo novas possibilidades às pessoas com deficiência, algumas das quais que seriam impensáveis, ainda há pouco tempo atrás". Em nosso estudo, identificamos alguns produtos eletrônicos direcionados ao apoio para orientação e mobilidade da pessoa com deficiência visual severa, a exemplo da bengala eletrônica. Porém, vale destacar que os produtos identificados ainda não se encontram disponíveis para utilização de crianças com perda visual severa na faixa etária estudada, o que indica o pouco investimento na pesquisa e no desenvolvimento de produtos digitais para esse público. Num contexto em que as tecnologias digitais se fazem cada vez mais presentes, e que, segundo Galvão Filho e Damasceno (2008), aquelas direcionadas às pessoas com deficiência vêm possibilitando otimização na utilização de Sistemas Alternativos e Aumentativos de Comunicaçáo, também sendo muito utilizadas para o controle do ambiente, tais como "comandar remotamente aparelhos eletrodomésticos, acender e apagar luzes", para o desenvolvimento de habilidades, para a vivência do lúdico, e para processos de construção do conhecimento de alunos com necessidades educacionais especiais, a falta de produtos digitais específicos para as crianças cegas de 0 a 5 anos evidencia o estágio em que se encontra o desenvolvimento tecnológico nessa área e/ou o pouco investimento feito para o atendimento dessas crianças.

Bersc (2013) enfatiza que muitas vezes "não se considera que as pessoas com deficiência são diferentes entre si, vivem em contextos diferentes e enfrentam problemas únicos de participação e desempenho de tarefas, nos lugares onde vivem". Assim, destacamos que, neste levantamento, constam os produtos de apoio mais utilizados por crianças cegas no desenvolvimento de habilidades motoras, isso não significa dizer que todas as crianças farão uso dos mesmos produtos, afinal, é preciso considerar aspectos como: as necessidades específicas e individuais, o contexto que a criança está inserida e as barreiras que impedem ou dificultam a execução da tarefa pelo indivíduo. Desta forma, as indicaçóes dos produtos assistivos devem seguir preceitos e critérios individualizados. 


\section{Considerações finais}

De acordo com Bueno (2010, p. 146), o desenvolvimento motor nas crianças cegas não é mais lento do que nas crianças videntes, o que ocorre é que a motivação pelo deslocamento se desenvolve num ritmo diferente em função da carência de entrada de informação visual. Sabendo que a visão e o movimento estão intimamente relacionados, é fundamental que, para minimizar as dificuldades de execução das atividades em nível sensorial e motor, a criança com perda visual severa receba estímulos que compensem ou diminuam as possíveis limitaçóes impostas pela perda visual.

Os resultados obtidos, no presente estudo, corroboram com os achados de Bueno (2010) que, ao realizar uma revisão bibliográfica acerca do desenvolvimento motor da criança cega, constatou serem insuficientes os estudos científicos, apesar dos avanços obtidos na área, por meio das pesquisas de Bruno (1993).

Quando analisamos as produçóes sobre os produtos assistivos que favoreçam a orientação, marcha e mobilidade da criança cega, a situação é ainda mais problemática, pois, além da escassez de estudos específicos sobre TA para este público na faixa etária estudada, verificamos, ainda, ser pouca ou quase nula a associação destes produtos como sendo uma TA. Ao longo deste estudo, também não identificamos produtos de apoio eletrônicos passíveis de utilização para OM de crianças cegas na faixa etária de 0 a 5 anos. Essas carências dificultam o acesso e difusão de informaçôes relevantes e úteis, assim como sua aplicação prática no cotidiano destas crianças. Sendo assim, se faz necessário que os estudos sobre Tecnologia Digitais e Tecnologia Assistiva avancem, de modo a favorecer, também, as crianças com perda visual severa em todas as faixas etárias.

Em face do acima exposto, torna-se evidente que a identificação, catalogação e descrição funcional dos produtos de TA, direcionados ao apoio para aquisição da orientação, mobilidade e marcha de crianças cegas na faixa etária de 0 a 5 anos, além da ampliação das produçóes acadêmicas sobre a temática abordada neste estudo, são de extrema relevância, especialmente no que tange às possibilidades de aplicações, de forma a minimizar possíveis limitaçóes funcionais que desfavoreçam o desenvolvimento sensório-motor das crianças não videntes, tornando estas mais independentes e seguras com relação a orientação, marcha e mobilidade.

\section{Referências}

BRASIL. Política Nacional de Educação Especial na Perspectiva da Educação Inclusiva. PORTAL MEC. Secretaria de Educação Especial - MEC/SEESP, 2008. Disponível em: <http://portal.mec.gov.br/arquivos/pdf/ politicaeducespecial.pdf>. Acesso em: 06 dez. 2013.

Nota técnica-SEESP/GAB/n. 09/2010 de 09 de abril de 2010 que fixa as orientaçôes para a organização de Centros de Atendimento Educacional Especializado. PORTAL MEC. 2010a. Disponível em: <http://portal. mec.gov.br/índex >. Acesso em: 06 dez. 2013.

Nota técnica-SEESP/GAB/n. 11/2010 de 07 de maio de 2010, que estabelece orientaçôes para a Institucionalizaçáo da Oferta do Atendimento Educacional Especializado - AEE em Salas de Recursos Multifuncionais implantadas nas escolas regulares. PORTAL MEC. 2010b. Disponível em: <portal.mec.gov.br/índex>. Acesso em: 06 jul. 2012. 
Nota técnica- MEC / SECADI / DPEE/n ${ }^{\circ}$ 55/2013 de 10 de maio de 2013, que estabelece orientaçóes à atuaçáo dos Centros de AEE, na perspectiva da educaçáo Inclusiva. Disponível em: <http://www. ppd.caop.mp.pr.gov.br >. Acesso em: 01 jan. 2014.

BERSCH, R. Recursos pedagógicos acessíveis: tecnologia assistiva (TA) e processo de avaliação nas escolas. 2013. Disponível em: <http://www.assistiva.com.br/>. Acesso em: 02 jan. 2014.

BRUNO, M. M. G. O desenvolvimento integral do portador de deficiência visual: da intervenção precoce à integraçáo escolar. São Paulo: NEWSWORK, 1993.

Deficiência visual: reflexão sobre a prática pedagógica. São Paulo: Laramara, 1997.

BUENO, S. T. Motricidade e deficiência visual. In: MARTÍN, M. B.; BUENO, S. T. Deficiência visual: aspectos psicoevolutivos e educativos. São Paulo: Santos, 2010.

CAT, 2007. Ata da Reuniáo VII, de dezembro de 2007, Comitê de Ajudas Técnicas, Secretaria Especial dos Direitos Humanos da Presidência da República (CORDE/SEDH/PR). Disponível em: <http://www.mj.gov.br/ corde/arquivos/doc/Ata_VII_Reuniāo_do_Comite_de_Ajudas_Técnicas.doc>. Acesso em: 05 fev. 2013.

DIEM, L. Os primeiros anos sáo decisivos: como desenvolver a inteligência das crianças desde o berço, pelo treino dos movimentos. 1. ed. Rio de Janeiro: Tecnoprint, 1980.

DUTRA, C. P. In: Orientaçáo e mobilidade: conhecimentos básicos para a inclusão do deficiente visual. Brasília: MEC, SEESP, 2003.

EFFGEN, S. K. Fisioterapia pediátrica: atendendo às necessidades das crianças. Rio de Janeiro: Editora Guanabara Koogan, 2007.

FARRELL, M. Deficiências sensoriais e incapacidades físicas: guia do professor. Porto Alegre: Artmed, 2008.

GALVÃO, N. C. S. S. Inclusão de crianças com deficiência visual na Educaçáo Infantil. 2005. 179 f. Tese (Mestrado em Educação). Faculdade de Educação, Universidade Federal da Bahia, Salvador, 2005.

GALVÃO FILHO, T. Tecnologia assistiva: favorecendo o desenvolvimento e a aprendizagem em contextos educacionais inclusivos. In: GIROTO, C. R. M.; POKER, R. B.; OMOTE, S. (Org.). As tecnologias nas práticas pedagógicas inclusivas. Marília: Cultura Acadêmica, 2012, p. 65-92.

GALVÃO FILHO, T. A.; DAMASCENO, L. L. Programa InfoEsp: premio Reina Sofia 2007 de rehabilitación y de ntegración. Boletín del Real Patronato Sobre Discapacidad. Madri: Ministerio de Educación, Política Social y Deporte de Espańa. n. 63, 2008, p. 14-23.

GARCIA, N. "Como" Desenvolver Programas de orientação e mobilidade para pessoas com deficiência visual. In: MACHADO, E. V. et al. Orientaçấo e mobilidade: conhecimentos básicos para a inclusão do deficiente visual - Brasília: MEC, SEESP, 2003.

LOPES, A. Dicionário ilustrado de Fisioterapia. 2. ed. Rio de Janeiro: Guanabara Koogan, 2008.

LORA, T. D. P. Descobrindo o real papel das outras percepções, além da visão, para a orientaçáo e mobilidade. In: MACHADO, E. V. et al. Orientaçáo e mobilidade: conhecimentos básicos para a inclusão do deficiente visual. Brasília: MEC, SEESP, 2003.

LUNDY-EKMAN, L. Neurociências: fundamentos para reabilitaçăo. 3. ed. Rio de Janeiro: Elsevier, 2008.

MACHADO, E. V. et al. Orientaçáo e mobilidade: conhecimentos básicos para a inclusão do deficiente visual. Brasília: MEC, SEESP, 2003.

MARTÍN, M. B. Visão subnormal. In: MARTÍN, M. B.; BUENO, S. T. Deficiência visual: Aspectos psicoevolutivos e educativos. São Paulo: Santos, 2010.

MASI, I. de. Conceitos - aquisição básica para a orientação e mobilidade. In: MACHADO, E. V. et al. Orientaçáo e mobilidade: conhecimentos básicos para a inclusão do deficiente visual. Brasília: MEC, SEESP, 2003.

OCHAÍTA, E.; ESPINOSA, M. Á. Desenvolvimento e intervenção educativa nas crianças cegas ou deficientes visuais. In: COLL, C. ; MARCHESI, Á.; PALACIOS, J. (Orgs.). Desenvolvimento psicológico e educaçáo; 2. ed. Porto Alegre: Artmed, 2004.3v.

RADABAUGH, M. P. Study on the Financing of Assistive Technology Devices of Services for Individuals with Disabilities - A report to the president and the congress of the United State, National Council on Disability, Março 1993. 
SARTORETTO, M. L.; BERSCH, R. Assistiva tecnologia e educaçáo. 2013. Disponível em: < http://www. assistiva.com.br/tassistiva.html>. Acesso em: 03 jan. 2014.

SHUMWAY-COOK, A.; WOOLLACOTT, M. H. Controle motor: teoria e aplicações práticas. 2. ed. São Paulo: Manole, 2003.

SIAULYS, M. de O. C. Brincar para todos. Brasília: Ministério da Educação. Secretaria de Educação Especial, 2005.

TEIXEIRA, A. P. et al. CRER-SER: Material de orientaçáo para pais, professores e amigos de crianças com deficiência visual. INSTITUTO DE CEGOS DA BAHIA. Centro de Intervenção Precoce. Salvador, 2010.

VIGOTSKY, L. S. A formaçáo social da mente. São Paulo: Martins Fontes, 1984.

VYGOTSKI, L. S. Acerca de la psicología y la pedagogía de la efectividad infantil. In L. S. Vygotski, Obras Escogidas V: Fundamentos de defectología. Madrid: Visor, 1997, p. 73-95.

\section{Notas}

${ }^{1}$ As consequências sociais da deficiência acentuam, alimentam e consolidam a própria deficiência. Neste problema não existe nenhum aspecto onde o biológico possa ser separado do social (tradução nossa)

2 Ex: Nota técnica n. 055 / MEC / SECADI / DPEE de 10 de maio de 2013 (BRASIL, 2013), que fixa as Orientaçóes à atuação dos Centros de AEE, na perspectiva da educaçáo inclusiva; e na nota técnica-SEESP/GAB/n. 11/2010 de 07 de maio de 2010 (BRASIL, 2010), que estabelece orientaçôes para a Institucionalização da Oferta do Atendimento Educacional Especializado - AEE, em Salas de Recursos Multifuncionais implantadas nas escolas regulares.

${ }^{3} \mathrm{O}$ aparelho vestibular, localizado no ouvido interno, contém receptores sensitivos que respondem aos movimentos e posição da cabeça em relação a gravidade. Essa informação é convertida em sinais neurais transmitidos pelo nervo vestibular para seus núcleos. Os núcleos vestibulares estấo localizados no tronco encefálico, na junção da ponte e do bulbo. As projeçôes dos núcleos vestibulares contribuem para: informaçóes sensoriais sobre o movimento e a posiçáo da cabeça em relaçáo a gravidade; estabilizaçáo do olhar; ajustes posturais; função autonômica da consciência ( LUNDY-EKMAN, 2008, p. 325)

${ }^{4}$ Aferente: o que transporta um líquido ou impulso nervoso para um órgão ou região (LOPES, 2003, p. 7).

${ }^{5}$ Tônus Muscular é o grau de resistência ao estiramento passivo exercido por um músculo em repouso (LUNDY-EKMAN, 2008, p. 454).

${ }^{6}$ Plasticidade Neural é a capacidade do sistema nervoso central para adaptação e reorganização. (LOPES, 2003, p. 176)

${ }^{7}$ Recursos são todo e qualquer item, equipamento ou parte dele, produto ou sistema fabricado em série ou sob medida, utilizado para aumentar, manter ou melhorar as capacidades funcionais das pessoas com deficiência.

${ }^{8}$ Progressão: é a garantia de um padrão locomotor básico, que produz e coordena padrōes rítmicos de ativação muscular nas pernas e no tronco, para movimentar o corpo na direção desejada; Estabilidade: reflete a necessidade de estabelecer e manter uma postura adequada para a locomoção e também a demanda da estabilidade dinâmica dos movimentos do corpo; Adaptação: adaptar o andar de acordo com os objetivos do indivíduo e as demandas do ambiente. (Shumway-Cook, 2003, p. 290).

${ }^{9}$ Entende-se por programa de atendimento e apoio especializado um conjunto de recursos e açóes educativas destinado à promoção do desenvolvimento integral e ao apoio ao processo de inclusão escolar das crianças com necessidades educacionais especiais, em interface com a área de saúde e de assistência social. (BRASIL, 2000, p.29).

${ }^{10}$ Atividade é a execução de uma tarefa ou ação por um indivíduo

${ }^{11}$ Participação é o envolvimento numa situação da vida

${ }^{12}$ Limitaçóes são dificuldades que um indivíduo pode encontrar na execução de atividades e as restriçốes de participaçáo são problemas que um indivíduo pode experimentar no envolvimento em situaçóes reais da vida

${ }^{13}$ A audiçáo é a capacidade de perceber o som, sendo que o órgão do sentido responsável pela audição é o ouvido. Destacamos para a OM a ecolalização que refere-se ao ato de produzir o som e perceber o eco refletido. Segundo Lora (2003, p. 59), a ecolalização também pode ser chamada de "visão facial, percepção de obstáculo e sexto sentido". 
${ }^{14}$ No tato, no que se refere à OM destaca-se a capacidade tátil de termocepção que é perceber a mudança de temperatura; além da propriocep̧̧ão ou cinestesia faz a diferença para o reconhecimento da localizaçấo espacial do corpo, pois "cinestesia é a sensibilidade para perceber os movimentos musculares ou das articulaçóes." (Lora, 2003, p. 62), sendo um dos pontos chave para caminhar com um guia no processo de orientaçáo e mobilidade.

${ }^{15} \mathrm{O}$ olfato é o sentido responsável por captar odores, sendo de grande referência para a criança cega perceber os distintos ambientes e odores característicos, como exemplo, o cheiro da comida que a mamãe prepara na cozinha e outros.

${ }^{16}$ Decúbito lateral (ficar deitado de lado)

${ }^{17}$ Decúbito ventral (ficar deitado de bruços)

\section{Correspondência}

Lana Tuan Borges de Jesus - Rua Marechal Hermes da Fonseca, 92 E, Bairro: Periperi, CEP: 40760-640. Salvador, Bahia, Brasil.

E-mail: lanatuanborges@hotmail.com - alexandrabispo23@gmail.com - bonilla@ufba.br

Recebido em 30 de abril de 2014

Aprovado em 20 de outubro de 2014 
